\title{
Use of Fc-Engineered Antibodies as Clearing Agents to Increase Contrast During PET
}

\author{
Rafal Swiercz ${ }^{1}$, Srinivas Chiguru ${ }^{2}$, Amir Tahmasbi $^{3}$, Saleh M. Ramezani ${ }^{2}$, Guiyang Hao ${ }^{2}$, Dilip K. Challa ${ }^{1}$, \\ Matthew A. Lewis ${ }^{2}$, Padmakar V. Kulkarni ${ }^{2}$, Xiankai Sun ${ }^{2}$, Raimund J. Ober ${ }^{1,3}$, Ralph P. Mason ${ }^{2}$, and E. Sally Ward ${ }^{1}$ \\ ${ }^{1}$ Department of Immunology, University of Texas Southwestern Medical Center, Dallas, Texas; ${ }^{2}$ Department of Radiology, University \\ of Texas Southwestern Medical Center, Dallas, Texas; and ${ }^{3}$ Department of Electrical Engineering, University of Texas at Dallas, \\ Richardson, Texas
}

Despite promise for the use of antibodies as molecular imaging agents in PET, their long in vivo half-lives result in poor contrast and radiation damage to normal tissue. This study describes an approach to overcome these limitations. Methods: Mice bearing human epidermal growth factor receptor type 2 (HER2)-overexpressing tumors were injected with radiolabeled $\left({ }^{124}\left|,{ }^{125}\right|\right)$ HER2-specific antibody (pertuzumab). Pertuzumab injection was followed $8 \mathrm{~h}$ later by the delivery of an engineered, antibody-based inhibitor of the receptor, FcRn. Biodistribution analyses and PET were performed at 24 and $48 \mathrm{~h}$ after pertuzumab injection. Results: The delivery of the engineered, antibody-based FcRn inhibitor (or Abdeg, for antibody that enhances IgG degradation) results in improved tumor-to-blood ratios, reduced systemic exposure to radiolabel, and increased contrast during PET. Conclusion: Abdegs have considerable potential as agents to stringently regulate antibody dynamics in vivo, resulting in increased contrast during molecular imaging with PET.

Key Words: engineered antibodies; PET; breast cancer; FcRn

J Nucl Med 2014; 55:1204-1207

DOI: 10.2967/jnumed.113.136481

\section{C} ombined with the development of engineering techniques to generate antibodies of high affinity and specificity for antigen, interest in the use of antibodies as diagnostic imaging agents is rapidly expanding. However, the long in vivo half-lives of antibodies result in high background levels, poor contrast, and radiation exposure of normal tissue (1-3). These problems are exacerbated when the tumor burden is low. These undesirable characteristics also limit the use of radioconjugated antibodies in therapy $(4,5)$. In the current study, we have developed an approach that results in the rapid clearance of unbound targeting antibody after tumor localization.

It is well established that the $\mathrm{Fc}$ receptor, FcRn, regulates the levels of antibodies of the IgG class in the body (6). This receptor binds to antibodies in acidic, early endosomal compartments after their fluid phase uptake into cells. Bound antibodies are recycled

Received Dec. 17, 2013; revision accepted Apr. 2, 2014.

For correspondence contact: E. Sally Ward, University of Texas Southwestern Medical Center, 6001 Forest Park Rd., Rm. ND6.310, Dallas, Texas 75390.

E-mail: Sally.Ward@utsouthwestern.edu

Published online May 27, 2014.

COPYRIGHT (c) 2014 by the Society of Nuclear Medicine and Molecular Imaging, Inc. or transcytosed and exocytosed, whereas unbound antibodies enter the endolysosomal pathway and are degraded $(7,8)$. We have described a class of engineered antibodies that bind with increased affinity through their $\mathrm{Fc}$ region to $\mathrm{FcRn}$ in the $\mathrm{pH}$ range of 6.0-7.4 (9). These antibodies compete with endogenous, wild-type IgGs for binding to FcRn and, as such, increase their degradation. Antibodies of this class have been called Abdegs, for antibodies that enhance $\operatorname{IgG}$ degradation. Levels of $\mathrm{IgG}$ are regulated by FcRn expression in hematopoietic and endothelial cells (10). Inhibition of FcRn by Abdegs therefore occurs at multiple diffuse sites in many different cell types throughout the body.

We have previously demonstrated that Abdegs can be used to clear autoreactive antibodies and ameliorate disease in mouse models of autoimmunity $(11,12)$. However, whether these inhibitors can be used to reduce both background levels and systemic exposure to radiolabeled antibody during PET is unexplored. In this setting, a balance between the reduction of background levels of unbound, radiolabeled antibody and the maintenance of sufficient tumor-bound antibody for imaging needs to be achieved. Thus, the tradeoff of minimizing systemic exposure to radiolabeled antibody using clearing agents is that the circulating imaging agent is no longer available to bind to tumor cells. In the current study, we have developed a regimen of Abdeg delivery that enables substantial reduction in background combined with improved contrast during PET.

\section{MATERIALS AND METHODS}

\section{Antibodies and Labeling}

Pertuzumab was obtained from the University of Texas Southwestern Medical Center Pharmacy and was labeled with ${ }^{124}$ I (IBA Molecular) or ${ }^{125}$ I (PerkinElmer) using the IODO-GEN reagent (Pierce) as described (9). Wild-type human IgG1 (anti-lysozyme) and a mutated derivative (Abdeg), MST-HN (Met252 to Tyr, Ser254 to Thr, Thr256 to Glu, His433 to Lys, Asn434 to Phe), were expressed and purified using methods described previously (9). Size-exclusion analyses using a Yarra 3U SEC-3000 column demonstrated that the MST-HN Abdeg migrates at the expected size for an $\mathrm{IgG}$, with no detectable levels of aggregates (data not shown).

\section{Mice and Tumor Implantation}

Animal procedures were approved by the Institutional Animal Care and Use Committee of the University of Texas Southwestern Medical Center. A small, approximately $0.5-\mathrm{cm}$ incision was made above mammary gland number 4 of anesthetized 8-wk-old severe combined immunodeficient BALB/c female mice (Jackson Laboratory). HCC1954 cells $\left(0.5 \times 10^{6}\right)(13)$ suspended in $0.1 \mathrm{~mL}$ of RPMI-1640/Matrigel (Corning Inc.) vehicle (50/50) were injected into the fat pad of mammary gland 
number 3 of each mouse using a 22-gauge needle. The incision was closed with a wound clip that was removed $7 \mathrm{~d}$ later.

\section{Biodistribution Studies and PET}

Nine days after tumor implantation, when tumors were approximately $5 \mathrm{~mm}$ in diameter, mice were divided into 3 equivalent groups (6 mice per treatment group) and injected intravenously with ${ }^{125} \mathrm{I}-$ labeled pertuzumab. Thyroid uptake of radiolabeled iodine was reduced by adding Lugol solution to drinking water $48 \mathrm{~h}$ before injection of radiolabeled pertuzumab $\left(2.96-3.33 \times 10^{6} \mathrm{~Bq}\right.$ [80-90 $\left.\mu \mathrm{Ci}\right], 60 \mu \mathrm{g} /$ mouse). Eight hours after pertuzumab injection, mice in each group were injected intravenously with $1 \mathrm{mg}$ of Abdeg (MST-HN mutant), 1 $\mathrm{mg}$ of wild-type IgG1, or vehicle (phosphate-buffered saline [PBS]). Blood samples were collected before perfusion of mice through the heart with $20 \mathrm{~mL}$ of PBS supplemented with $10 \mathrm{U} / \mathrm{mL}$ heparin at 24 or $48 \mathrm{~h}$ after pertuzumab injection (i.e., 16 and $40 \mathrm{~h}$ after delivery of Abdeg, wild-type IgG1, or PBS). After perfusion, organs and tumors were harvested and weighed, and radioactivity levels were determined by $\gamma$ counting. Whole-body counting was performed using a dose calibrator (Capintec Inc.).

For PET, ${ }^{124}$ I-labeled pertuzumab was used and stomach uptake of radiolabeled iodine was blocked by gastric lavage with $1.5 \mathrm{mg}$ of potassium perchlorate in $0.2 \mathrm{~mL}$ of PBS $30 \mathrm{~min}$ before injection of radiolabeled antibody. PET/CT was performed $4 \mathrm{~h}$ after injection of radiolabeled antibody (80-90 $\mu \mathrm{Ci}, 60 \mu \mathrm{g}$ antibody/mouse). For each mouse, CT images were acquired immediately before PET imaging. Eight hours after injection of radiolabeled pertuzumab, mice were injected intravenously with $1 \mathrm{mg}$ of Abdeg (MST-HN mutant), 1 $\mathrm{mg}$ of wild-type $\mathrm{IgG1}$, or vehicle (PBS). PET/CT was repeated at 24 and $48 \mathrm{~h}$ after radiolabeled pertuzumab injection.

\section{Image Acquisition and Analysis}

Details of data analyses for PET are described in the supplemental data (supplemental materials are available at http://jnm.snmjournals.org).

\section{Statistics}

Statistical analyses were performed as described in the supplemental data.

\section{RESULTS}

\section{Biodistribution Studies}

The FcRn inhibitor, or Abdeg, used for these studies is a mutated variant (MST-HN) of human wild-type IgG1 that has substantially higher affinity for FcRn binding because of 5 amino acid replacements near the FcRn interaction site (9). In earlier studies, we demonstrated that a dose of $1 \mathrm{mg}$ of MST-HN Abdeg $(\sim 50 \mathrm{mg} / \mathrm{kg})$ per mouse is optimal for inducing the clearance of lower-affinity, competing IgGs in vivo (11), and this dose was therefore used here. Tumor-bearing mice (HCC1954 cells; diameter of tumors, $\sim 5 \mathrm{~mm}$ ) were injected with ${ }^{125}$ I-labeled pertuzumab $9 \mathrm{~d}$ after tumor implantation. Groups of mice were injected with Abdeg $8 \mathrm{~h}$ after pertuzumab delivery. Our preliminary studies indicated that treatment with Abdeg at a shorter time interval resulted in lower tumor-to-blood ratios of antibody (data not shown). As controls, the wild-type IgG1 parent molecule (1 mg/mouse) and PBS vehicle were used throughout these studies.

Biodistribution analyses at $24 \mathrm{~h}$ after delivery of radiolabeled pertuzumab $(16 \mathrm{~h}$ after Abdeg treatment) demonstrated that the levels of radiolabel were lower in the heart, lungs, and kidneys of Abdeg recipients (Fig. 1A). Similar results were obtained at $48 \mathrm{~h}$ after pertuzumab injection $(40 \mathrm{~h}$ after Abdeg treatment), except that radioactivity levels in the liver were also reduced (Fig. 1A). In addition, the tumor-to-blood ratios were approximately 3 -fold higher in Abdeg-treated mice than in mice in control groups (Figs. 1B and 1C). The whole-body counts of ${ }^{125}$ I-labeled pertuzumab after Abdeg delivery were substantially decreased relative to those in the control groups, with approximately 2.5 - and 7-fold differences at 16 and $40 \mathrm{~h}$ after Abdeg treatment, respectively (Fig. 1D). Tumor levels of radiolabeled antibody were also reduced by Abdeg treatment, and this is particularly marked at $48 \mathrm{~h}$ after pertuzumab delivery (Fig. 1C). This finding suggests de novo human epidermal growth factor receptor type 2 biosynthesis by tumor cells or tumor growth during the course of the experiment, resulting in new antigen 
exposure that is targeted less efficiently by the reduced circulating pertuzumab concentrations induced by Abdeg delivery. The reduction of radiolabeled antibody levels in the tumor, in combination with our goal of using Abdegs to decrease the time period between delivery of imaging agent and PET, indicated that biodistribution analyses at time points beyond $48 \mathrm{~h}$ would not be informative.

\section{Imaging Studies}

We next used PET to analyze the effects of Abdeg delivery on the disposition of radiolabeled pertuzumab at the whole-body level. Imaging of the mice at $4 \mathrm{~h}$ after radiolabeled $\left({ }^{124} \mathrm{I}\right)$ pertuzumab delivery, before Abdeg treatment, indicated tumor localization but with a diffuse distribution of labeled antibody throughout the body (Fig. 2). By contrast, within $16 \mathrm{~h}$ of Abdeg treatment ( $24 \mathrm{~h}$ after pertuzumab delivery), levels of radiolabeled antibody throughout the body, particularly in the thorax, were markedly reduced relative to those in the control groups (wild-type IgG1, PBS) (Fig. 2; Sup-

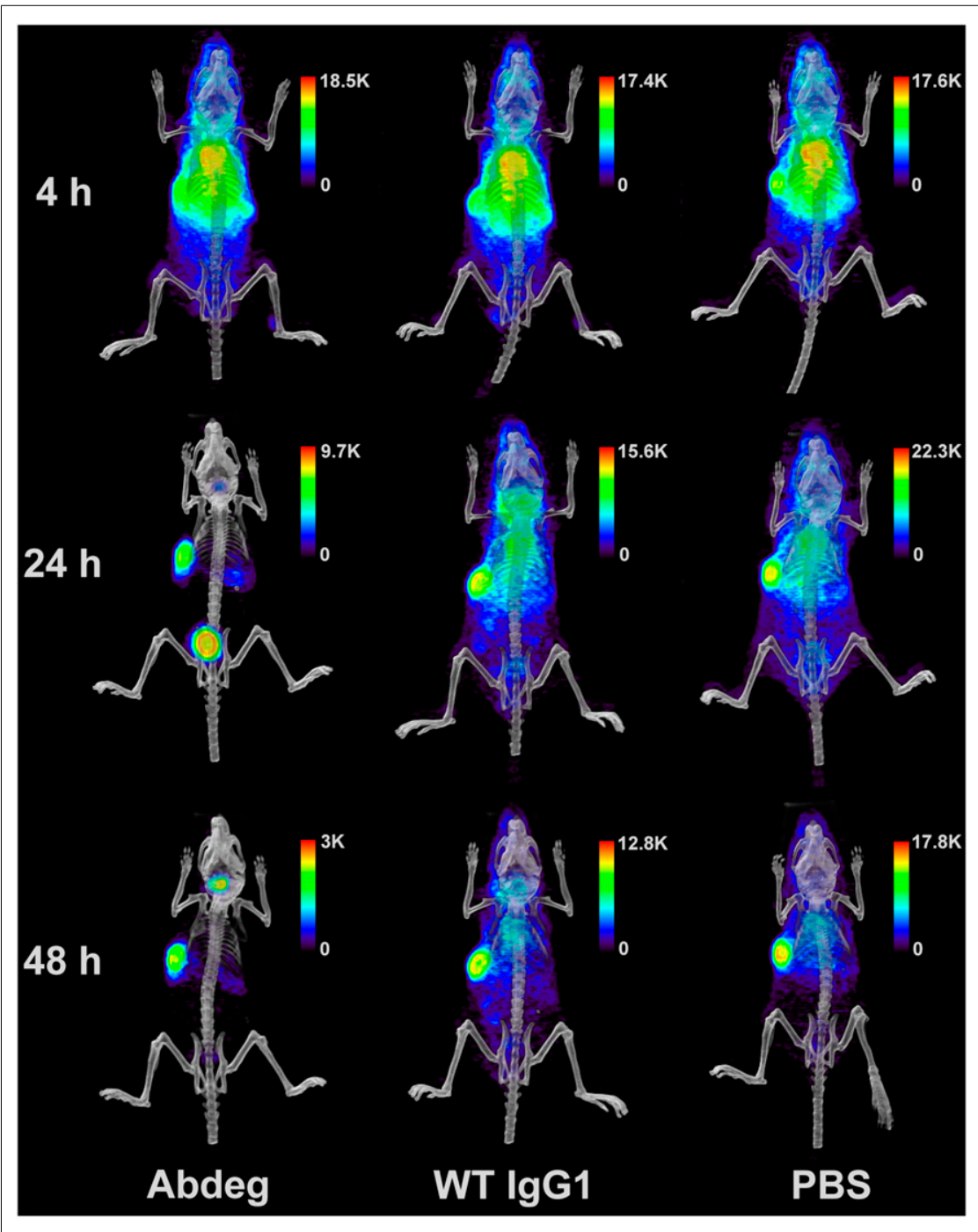

FIGURE 2. PET analyses of radiolabeled pertuzumab after Abdeg delivery. Tumor-bearing mice were treated as in Figure 1, except that ${ }^{124}$-labeled pertuzumab was used. PET/CT data acquired at 4,24 , and $48 \mathrm{~h}$ after injection of radiolabeled antibody ( 3 mice per group; 1 mouse per treatment is shown). These time points correspond to $4 \mathrm{~h}$ before and 16 and $40 \mathrm{~h}$ after treatment with Abdeg or controls. Linear scale bars are shown. Data are representative of 2 experiments, each with 3 mice per treatment group. WT = wild type. plemental Videos 1-3). At $24 \mathrm{~h}$ after pertuzumab injection, accumulation of radiolabel in the bladder of Abdeg-treated mice was high because of the enhanced catabolism of radiolabeled antibody. Similar results were obtained using PET at $48 \mathrm{~h}$ after radiolabeled pertuzumab delivery, except that the bladder accumulation was reduced (Fig. 2). Importantly, Abdeg treatment resulted in approximately a 4-fold-higher contrast for the radiolabeled antibody than that for mice in the 2 control groups (Fig. 3).

\section{DISCUSSION}

We demonstrate that Abdegs can be used to enhance contrast and reduce exposure of normal tissue to radiolabeled antibody during diagnostic imaging. Further, the higher contrast could enable the use of lower doses of radiolabeled imaging agents. Typically, the use of antibodies for diagnostic imaging in humans necessitates a wait period of 4-7 d between the delivery of the radiolabeled antibody and imaging due to the long in vivo half-lives of antibodies $(14,15)$. By contrast, the use of Abdegs as clearing agents should enable this time period to be considerably reduced. Thus, Abdegs not only decrease systemic exposure to radiolabel, but also could have significant practical advantages in clinical settings.

Alternative approaches toward achieving reduced background during imaging include decreasing the in vivo half-life of the diagnostic antibody itself by mutagenesis or the deletion of one or more $\mathrm{Fc}$ region domains $(16,17)$. However, rapid clearance of the imaging agent immediately after injection can limit tumor localization (4). In addition, although intravenous gammaglobulin (IVIG) has been shown to have efficacy in clearing radiolabeled antibodies during imaging, high doses are necessary because of the relatively poor competitive activity of the wild-type IgGs present in IVIG for FcRn binding (3). Indeed, IVIG treatment at a dose of $1 \mathrm{~g} / \mathrm{kg}$ has recently been shown to be ineffective in reducing blood-pool levels of a radiolabeled imaging agent in patients (14). Consistent with the higher affinity of the MST-HN Abdeg, compared with wild-type IgGs, for binding to FcRn, in earlier studies we observed that 25- to 50-fold-higher doses of IVIG relative to the MST-HN Abdeg were necessary to induce similar decreases in IgG levels and amelioration of disease in a mouse model of arthritis (11). In addition, Abdegs themselves have short in vivo half-lives because of their retention within cells and lysosomal degradation (18). Thus, effects on the levels of endogenous IgGs are short-lived, with return to normal levels in mice within 3-4 d of treatment (9). By comparison, the longer in vivo persistence of IVIG results in reductions in 


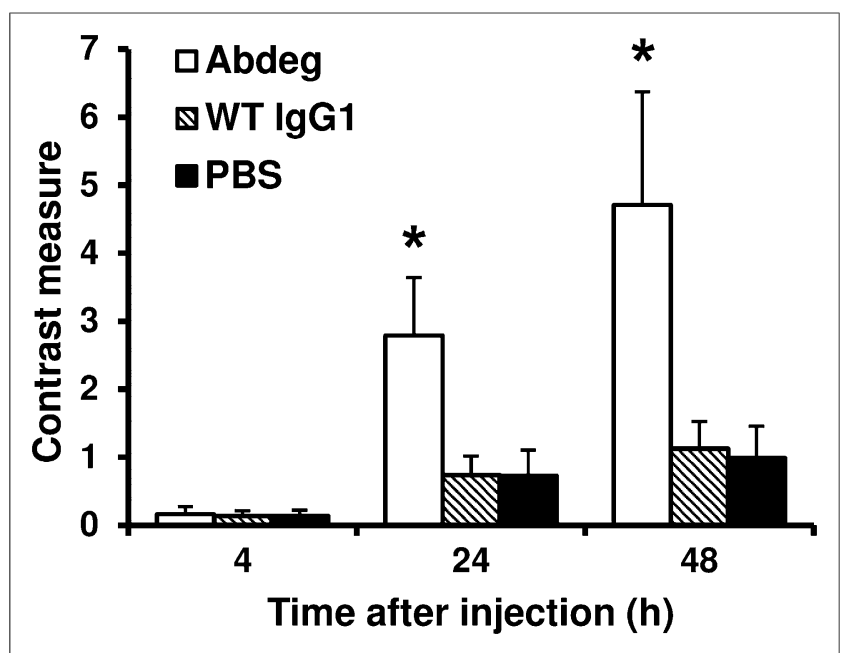

FIGURE 3. Effect of Abdeg delivery on PET contrast. Tumor-bearing mice were treated as in Figure 2. Contrast measures at 4, 24, and $48 \mathrm{~h}$ after injection of radiolabeled pertuzumab are shown. * indicates that values for Abdeg-treated mice and mice in control groups are significantly different (ANOVA, 99\% confidence intervals). Data shown are mean values + SD from 2 experiments, each with 3 mice per treatment group. WT $=$ wild type.

IgG levels and other anti-inflammatory effects for prolonged periods $(19,20)$.

\section{CONCLUSION}

The improved contrast resulting from Abdeg delivery, combined with the rapid and tightly controlled reduction in systemic radiolabeled antibody levels, demonstrates that this class of engineered antibodies has considerable promise for use in diagnostic imaging.

\section{DISCLOSURE}

The costs of publication of this article were defrayed in part by the payment of page charges. Therefore, and solely to indicate this fact, this article is hereby marked "advertisement" in accordance with 18 USC section 1734. This study was supported in part by grants from the Cancer Prevention and Research Institute of Texas (CPRIT; RP 110070 and RP 110441) and the Simmons Cancer Center support grant (5P30 CA 142543). E. Sally Ward is an inventor on a patent (owned by University of Texas Southwestern Medical Center) related to the use of Abdegs as FcRn inhibitors. No other potential conflict of interest relevant to this article was reported.

\section{ACKNOWLEDGMENTS}

We are grateful to Drs. John Minna, Adi Gazdar, and Kenneth Huffman for providing the HCC1954 breast cancer cell line.

\section{REFERENCES}

1. Goldstein R, Sosabowski J, Vigor K, Chester K, Meyer T. Developments in single photon emission computed tomography and PET-based HER2 molecular imaging for breast cancer. Expert Rev Anticancer Ther. 2013;13:359-373.

2. Wu AM. Antibodies and antimatter: the resurgence of immuno-PET. J Nucl Med. 2009;50:2-5.

3. Jaggi JS, Carrasquillo JA, Seshan SV, et al. Improved tumor imaging and therapy via i.v. IgG-mediated time-sequential modulation of neonatal $\mathrm{Fc}$ receptor. $J$ Clin Invest. 2007;117:2422-2430.

4. Goldenberg DM, Chang CH, Rossi EA, McBride JW, Sharkey RM. Pretargeted molecular imaging and radioimmunotherapy. Theranostics. 2012;2:523-540.

5. Palanca-Wessels MC, Press OW. Improving the efficacy of radioimmunotherapy for non-Hodgkin lymphomas. Cancer. 2010;116:1126-1133.

6. Ward ES, Ober RJ. Multitasking by exploitation of intracellular transport functions: the many faces of FcRn. Adv Immunol. 2009;103:77-115.

7. Ober RJ, Martinez C, Vaccaro C, Zhou J, Ward ES. Visualizing the site and dynamics of IgG salvage by the MHC class I-related receptor, FcRn. J Immunol. 2004; 172:2021-2029.

8. Ober RJ, Martinez C, Lai X, Zhou J, Ward ES. Exocytosis of IgG as mediated by the receptor, FcRn: an analysis at the single-molecule level. Proc Natl Acad Sci USA. 2004;101:11076-11081.

9. Vaccaro C, Zhou J, Ober RJ, Ward ES. Engineering the Fc region of immunoglobulin G to modulate in vivo antibody levels. Nat Biotechnol. 2005;23:12831288.

10. Montoyo HP, Vaccaro C, Hafner M, Ober RJ, Mueller W, Ward ES. Conditional deletion of the MHC Class I-related receptor, FcRn, reveals the sites of IgG homeostasis in mice. Proc Natl Acad Sci USA. 2009;106:2788-2793.

11. Patel DA, Puig-Canto A, Challa DK, Perez Montoyo H, Ober RJ, Ward ES. Neonatal Fc receptor blockade by Fc engineering ameliorates arthritis in a murine model. J Immunol. 2011;187:1015-1022.

12. Challa DK, Bussmeyer U, Khan T, et al. Autoantibody depletion ameliorates disease in murine experimental autoimmune encephalomyelitis. MAbs. 2013;5:655-659.

13. Gazdar AF, Kurvari V, Virmani A, et al. Characterization of paired tumor and non-tumor cell lines established from patients with breast cancer. Int J Cancer. 1998;78:766-774.

14. Carrasquillo JA, Pandit-Taskar N, O'Donoghue JA, et al. ${ }^{124}$ I-huA33 antibody PET of colorectal cancer. J Nucl Med. 2011;52:1173-1180.

15. Knowles SM, Wu AM. Advances in immuno-positron emission tomography: antibodies for molecular imaging in oncology. J Clin Oncol. 2012;30:3884-3892.

16. Olafsen T, Betting D, Kenanova VE, et al. Recombinant anti-CD20 antibody fragments for small-animal PET imaging of B-cell lymphomas. J Nucl Med. 2009;50:1500-1508.

17. Pavlinkova G, Beresford GW, Booth BJ, Batra SK, Colcher D. Pharmacokinetics and biodistribution of engineered single-chain antibody constructs of MAb CC49 in colon carcinoma xenografts. J Nucl Med. 1999;40:1536-1546.

18. Gan Z, Ram S, Vaccaro C, Ober RJ, Ward ES. Analyses of the recycling receptor, FcRn, in live cells reveal novel pathways for lysosomal delivery. Traffic. 2009;10: 600-614.

19. Stangel M, Pul R. Basic principles of intravenous immunoglobulin (IVIg) treatment. J Neurol. 2006;253(suppl 5):V18-V24.

20. Clynes R. Protective mechanisms of IVIG. Curr Opin Immunol. 2007;19:646-651. 